\title{
Associative asymmetry, availability, and retrieval
}

\author{
DAVID C. RUBIN \\ Duke University, Durham, North Carolina 27706
}

\begin{abstract}
Associative frequency, the ease with which a word comes to mind in free association, is taken as a measure of general response availability. As expected from this view, in both controlled experiments and in reanalyses of previously published correlational data, high associative frequency words were judged to be more familiar and were easier to recall but harder to recognize than low associative frequency words, even with meaningfulness, imagery, length in letters, and frequency excluded as factors. When used as foils in a recognition experiment, high associative frequency worde attracted more responses than low associative frequency words. In addition, associative frequency and meaningfulness correlated only moderately and had different patterns of correlations with other variables, suggesting that the number of associations leading to and from a word differ.
\end{abstract}

Words that come to mind easily, that is, words that are available, are generally thought to be easier to recall. Although this idea has been tested for many specific subdomains or categories of words (e.g., Asch \& Ebenholtz, 1962; Dale, 1967; Deese, 1965; Leicht, 1968; Tversky \& Kahneman, 1973), with the exception of frequency of occurrence, no general measure of availability has been formulated. One main hindrance to such a formulation from an associative or network framework may be the failure to apply the evidence that associations among words are often asymmetrical (Anisfeld \& Knapp, 1968; Deese, 1965; Ekstrand, 1966; Paivio, 1971; Thorndike, 1932; cf. Asch \& Ebenholtz, 1962, and Horowitz, Norman \& Day, 1966). If associations are not always symmetrical, then meaningfulness, a measure of the number of associations emanating from a word, is not the general indicator of associative strength that it is held to be. An additional measure, the number of associations leading to a word, is also needed. Moreover, the number of associations leading to a word should be a good index of how often a word would be evoked over a sample of stimuli and, thus, should be a good index of response availability. ${ }^{1}$

Associative frequency is the number of times a word is given as a first associate to a sample of stimulus words, here the 200 stimulus words of Palermo and Jenkins (1964). Thus, associative frequency can be thought of as a general measure of availability for isolated words. That is, although certain words are more likely to come

Support for this research came from a Duke University Research Council Award. The author is indebted to Reed Hunt, Gregory Kimble, and Gregory Lockhead for their comments on an earlier version of the manuscript, and to Allan Paivio for making his familiarity ratings available. Reprints are available from the author, Psychology Department, Duke University, Durham, North Carolina 27706. to mind in the context of a category name (Dale, 1967), a list of other words (Deese, 1965), or an associated word (Tversky \& Kahneman, 1973), high associative frequency words are more likely to come to mind in general. In Underwood's (1965) terms, associative frequency is a measure of average frequency of a word as an implicit associative response. In a directed graph (Kiss, 1968, 1975), associative frequency is indegree value.

If the assumption that associations are asymmetrical and the assumption that associative frequency is a good measure of availability are correct, what predictions can be made? From the first assumption, it should follow that associative frequency and meaningfulness should not be the same variable. From the second assumption, it should follow that high associative frequency words should be easier to retrieve in free recall, harder to recognize, more effective as foils, and more familiar in judgment tasks. The prediction about recall follows from almost any model of retrieval. The predictions about recognition follow directly from Glanzer and Bowles (1976), as well as from Mandler (1980) and other accounts of recognition that have dealt with a similar problem, the word-frequency effect. The prediction about familiarity follows directly from Tversky and Kahneman (1973).

In order to examine some of the predictions made, one of the few studies that has investigated associative frequency, the one that led to this investigation, will be examined. As part of a large correlational study using 125 words (Rubin, 1980), 34 independent variables were used to predict which words would be remembered in various tasks. The independent variables included length in letters, orders of approximation to English, using letters and phonemes, orthographic distinctiveness, pronunciability, imagery, concreteness, meaningfulness, categorizability, age of acquisition, 
frequency counts, goodness, emotionality, associative frequency, and assorted others. Dependent variables included paired associate learning and free recall with 18 words/list and a 5 -sec presentation, free recall with all 125 words shown in one long list for $1 \mathrm{sec}$ each, surprise free recall following a lexical decision task, and surprise free recall following a paired associate task.

From this study, it is possible to provide an initial evaluation of both the claim that associative frequency should be an effective predictor of free recall and the claim that it should function differently from meaningfulness. The correlation of associative frequency and meaningfulness, calculated over the 125 words used in the study, is .42 . This should be considerably lower than the reliabilities of the two variables in this sample of words, as both variables correlate more highly with other variables in the study. Examinations of how the two variables function in memory tasks, however, are more revealing.

Meaningfulness is the ease with which a word brings other words to mind. Lists of high meaningfulness words should, therefore, be easy to learn, because each word in the list might lead to the recall of many others. However, the probability of any given word being recalled should depend on how easily it comes to mind, not on how easily it brings other words to mind. That is, associative frequency should be a better predictor of recall than meaningfulness. Rubin (1980) bears this out. On the seven independent free-recall tasks used, associative frequency correlated more highly with the percentage of subjects recalling each of 125 words than did meaningfulness, with average correlations with the recall tasks of .40 and .23 , respectively. In fact, associative frequency was the best single predictor, of 34 predictors, for most of the free-recall tasks. (In this and all other correlations reported, the logarithms of associative frequency and of frequency are used.)

The added control of paired associate learning allows a more direct test. If meaningfulness is a measure of how easily a word brings other words to mind, and if associative frequency is a measure of how easily other words bring the word in question to mind, then one would expect high meaningfulness words to be good stimulus words in paired associate learning, and high associative frequency words to be good response words. In Rubin (1980), 125 words plus a dummy word were made into 63 pairs. The first subject saw these pairs in a paired associate task, and the next subject saw the same pairs with the stimulus and response members interchanged. Various random pairings and orders were used. The number of times each pair of words was recalled was tabulated separately for both the stimulus and the response word. In this way, subjects and either the response or the stimulus words were averaged over, leaving only the stimulus or the response words determining the recall score. Meaningfulness correlated .47 with the scores tabulated by stimulus words, but only .21 with the same scores tabulated by response words. On the other hand, associative frequency correlated only .27 with the scores tabulated over stimulus words, but .58 with the scores tabulated by response words.

Although associative frequency is not the same as meaningfulness, it still could be the same as frequency. Frequency is a measure of how easily words come to mind in running text (Skinner, 1936), whereas associative frequency is a measure of how easily words come to mind in isolation (Ervin, 1963). In fact, Howes (1957) attempted to demonstrate that frequency in normal usage and frequency in association experiments are empirically the same. Howes showed statistically that if the complete range of word frequency and associative frequency, not just the relatively few common words that occur more than once per million or more, could be measured and used, the correlation would be .94 and probably higher. Nonetheless, over the limited range of words with a frequency of approximately 1 per million and greater and an associative frequency of approximately 1 per 600,000 and greater, the correlation is lower: $.55-.80$ for the five frequency counts used by Rubin (1980). As the words mentioned in a sample of one million words are typical of the words that make up most of English usage (Rubin, 1974) and most psychology experiments, the lower correlations provide a fairer index of the agreement of associative frequency and frequency in actual use. More important, the two variables behave differently in the Rubin (1980) study and elsewhere. Of special note is the observation that frequency is not a good predictor of free recall in studies using lists of mixed, as opposed to uniform, frequency (Christian, Bickley, Tarka, \& Clayton, 1978; Peters, 1936; Rubin, 1980; Rubin \& Corbett, 1982), whereas associative frequency is often the best predictor of free recall for mixed frequency lists (Rubin, 1980). That is, in mixed frequency lists, usually only a weak linear relation is found between frequency and recall, with rare words often showing greater recall than common words (e.g., Duncan, 1974; Gregg, 1976; Peters, 1936; Rubin \& Corbett, 1982), a reversal of the finding with uniform frequency lists and in a direction opposite to that found with associative frequency. Nevertheless, frequency and associative frequency do correlate fairly highly, and care must be taken to separate the two variables.

Thus, in one sample of 125 words using many memory tasks and independent variables, associative frequency emerges as one of our best predictors of free recall. Although theoretically related to and empirically correlated with meaningfulness and frequency, it does appear to be a separate variable. Nevertheless, one sample is not enough. The value of associative frequency in predicting free recall will be assessed in a correlational study with a new, larger sample of words, and then in a more controlled experiment. The claim that associative 
frequency is a good measure of availability will then be further examined using a recognition study and familiarity judgments.

\section{EXPERIMENT 1: A REGRESSION ANALYSIS}

The usefulness of associative frequency relative to other more standard variables and associative frequency's relation to those variables can best be assessed in a correlational study. Such a study should use a large number of words that cover a good range of values of the variables to be compared. Recall values are currently available for only one such set of words. Christian et al. (1978) had subjects recall lists of words using a standard list-learning paradigm in order to obtain percentage recalled values for 899 of Paivio, Yuille, and Madigan's (1968) 925 nouns. A total of 32 subjects saw each word. The resulting percentage of recalled values had a reliability of .57 .

Two cautions must be exercised, however, in using the Christian et al. (1978) values. First, 121 of the 899 nouns overlap with the Rubin (1980) study, making the total set not completely independent of the study originally arguing for the value of associative frequency. Second, for the 121 words that overlapped with the Rubin (1980) study, the Christian et al. measure was not the most representative recall task, having the highest correlations by a notable amount with both imagery and associative frequency. On the positive side, because Christian et al. used Paivio et al.'s (1968) words, values of imagery, meaningfulness, and other variables are available.

Including many variables in a multiple regression analysis can lead to technical problems, especially if some of the variables are highly correlated (Rubin, 1980). For this reason, a small subset of possible predictors of free recall was chosen for the regression analysis. Rubin (1980) found that six factors underlie most of the experimental tasks and variables that psychologists use. These factors, if labeled by their highest loading variables, would be length in letters, concreteness, log KuXera and Francis (1967) frequency, recall, emotionality, and goodness. Associative frequency did not appear as a separate factor but loaded $.44, .35, .61, .25$, .13 , and .05 , respectively, on the six factors listed. Values for the variables that label the first three factors are available and could be included in a multiple regression analysis along with associative frequency. Values for goodness and emotionality are not available, and recall is the dependent variable in question. Because imagery appears to be a better predictor of recall than concreteness (Christian et al., 1978; Frincke, 1968; Paivio, 1968; Rubin, 1980), imagery will replace concreteness in the analyses. In addition, meaningfulness will be included because of its theoretical relation to associative frequency.

\section{Results and Discussion}

Associative frequency values were calculated for Paivio et al.'s (1968) 925 nouns, using Palermo and Jenkins' (1964) word association norms. Following Rubin (1980), responses listed in the index of Palermo and Jenkins, but not in the actual tables, were assumed to have a frequency of 2 . The 460 nouns with values greater than 0 are given in Table 1. Correlations for the 925 nouns among available variables are listed in Table 2 . Because many of the words have associative frequency values of 0 , the correlations with $\log$ associative frequency were done both with these 0 values set to .5 before the logs were taken and with the 0 values omitted.

Multiple regressions were performed for all 899 words, for the 450 of the 899 words that had associative frequencies greater than 0 , and for the 346 of the 899 words that had associative frequencies greater than 0 and that were not included in Rubin's (1980) study. The last set of words was used to exclude the sample on which associative frequency and recall were first found to be related. The standardized regression weights (betas) and the increases in $\mathrm{R}^{2}$ when each variable is entered in to the regression equation last are given for the three analyses in Table 3 . The three analyses, fortunately, provided similar conclusions, although the effects of associative frequency were reduced somewhat when its range was reduced by eliminating its 0 values. Imagery was the best predictor, with associative frequency providing a good deal of independent predictive power, increasing the variance accounted for by imagery, meaningfulness, frequency, and length combined by between $12 \%$ and $20 \%$ in the three analyses. The multiple regression coefficients themselves are impressive, considering that the recall variable had a reliability of only .57 .

Rubin's (1980) finding that associative frequency is a good predictor of recall, both by itself and when used with other standard variables, is supported by Experiment 1 . The regression analysis allows comparisons to be made among many variables but suffers from two main limitations. First, the recall measure used may not have been representative of other recall measures (Rubin, 1980). Second, the units of analysis were words, not people, so the units were not independent, and inferential statistics could not be applied. Although the same basic finding was obtained for two samples of words and a total of seven independent free recall measures, a simple inferential test that varies associative frequency while holding as many other variables constant as possible is still lacking.

\section{EXPERIMENT 2: A CONTROLLED EXPERIMENT}

The main decision in designing the controlled experiment was to decide which of the multitude of variables 
Table 1

Nonzero Associative Frequency Values for Paivio et al.'s (1968) Norms

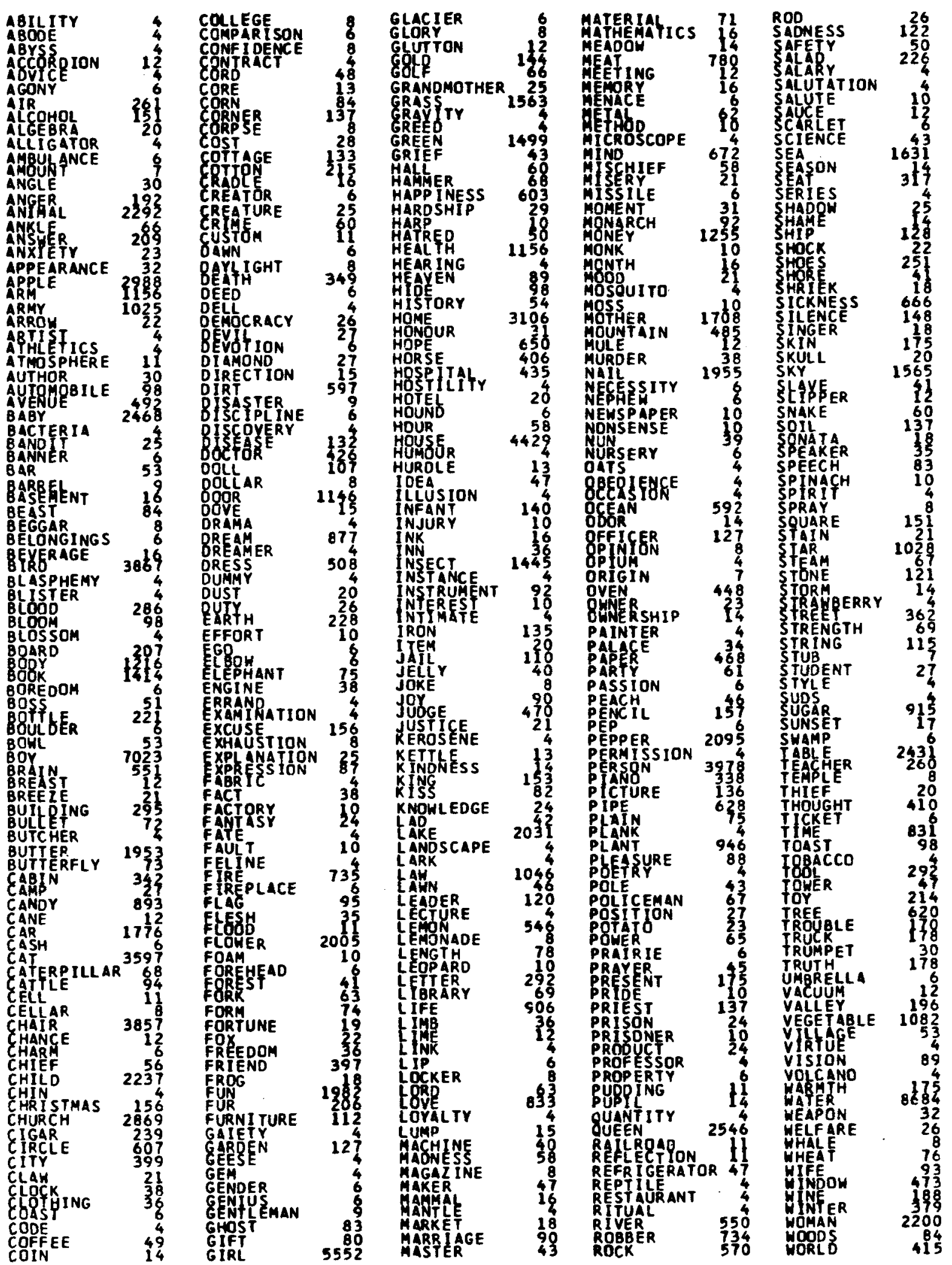


Table 2

Correlation Coefficients Among Variables

\begin{tabular}{|c|c|c|c|c|c|c|c|c|c|c|}
\hline & 3 & 4 & 5 & 6 & 7 & 8 & 9 & 10 & 11 & 12 \\
\hline 1. Log Associative Frequency & -.50 & .50 & .51 & .43 & .29 & .46 & .63 & .57 & .66 & .38 \\
\hline 2. Log Associative Frequency: No Zeros & -.33 & .33 & .35 & .31 & .24 & .32 & .56 & .46 & .53 & .40 \\
\hline 3. Length in Letters & & -.97 & -.92 & -.35 & -.30 & -.33 & -.27 & -.27 & -.41 & -.27 \\
\hline 4. First-Order Approximation & & & .93 & .32 & .28 & .32 & .28 & .30 & .43 & .25 \\
\hline 5. Second-Order Approximation & & & & .28 & .24 & .29 & .31 & .34 & .46 & .23 \\
\hline 6. Imagery & & & & & .83 & .72 & .34 & .09 & .33 & .44 \\
\hline 7. Concreteness & & & & & & .56 & .10 & -.06 & .16 & .40 \\
\hline 8. Meaningfulness & & & & & & & .48 & .28 & .43 & .31 \\
\hline 9. Familiarity & & & & & & & & .76 & .76 & .13 \\
\hline 10. Log Kučera-Francis Frequency & & & & & & & & & .77 & .09 \\
\hline 11. Log Thorndike-Lorge Frequency & & & & & & & & & & .17 \\
\hline 12. Free Recall & & & & & & & & & & \\
\hline
\end{tabular}

Note-Correlations are based on 925 words, except for free recall, which is based on 899 words, and log associative frequency with no zero values included, which is based on 460 words. First-and second-order approximations to English are information theory measures of the probability of generating the word by chance on a letter-by-letter basis (values from Rubin, 1981). Variable 6, 7, and 8 are from Paivio et al. (1968); Variable 9 is judged printed familiarity from Paivio (Note 1). For Variables 10 and 11 , zero frequencies were replaced by.5 and $A$ and $A A$ words were replaced by 50 and 100 , respectively.

Table 3

Multiple Regressions on Percentage Recalled

\begin{tabular}{|c|c|c|c|c|c|c|}
\hline \multirow[b]{3}{*}{ Variable } & \multicolumn{6}{|c|}{ Sample } \\
\hline & \multicolumn{2}{|c|}{$\begin{array}{c}\text { Overall } \\
(\mathrm{R}=.505, \mathrm{~N}=899) \\
\end{array}$} & \multicolumn{2}{|c|}{$\begin{array}{c}\mathrm{AF}>0 \\
(\mathrm{R}=.553, \mathrm{~N}=450) \\
\end{array}$} & \multicolumn{2}{|c|}{$\begin{array}{l}\text { AF }>0 \text { No Overlap } \\
(\mathrm{R}=.526, \mathrm{~N}=346)\end{array}$} \\
\hline & Beta Weight & $\mathrm{R}^{2}$ Increase & Beta Weight & $\mathrm{R}^{2}$ Increase & Beta Weight & $\mathbf{R}^{2}$ Increase \\
\hline Imagery & .356 & .053 & .378 & .073 & .356 & .068 \\
\hline Log Associative Frequency & .299 & .042 & .239 & .034 & .201 & .029 \\
\hline Log Kučera-Francis Frequency & -.108 & .007 & -.125 & .000 & -.018 & .000 \\
\hline Meaningfulness & -.067 & .002 & -.008 & .000 & .030 & .000 \\
\hline Length & -.049 & .002 & .009 & .014 & -.145 & .019 \\
\hline
\end{tabular}

Note-R = multiple-regression coefficient; $N=$ number of words in sample. The $R^{2}$ increase is the increase when the variable is entered into the multiple-regression equation after the four other independent variables.

that are related to recall to control. An attempt was made to control the same variables that were included in the multiple regression analysis in Experiment 1 for the same reasons that they were included there.

\section{Method}

Subjects. As part of a course requirement, 70 undergraduates participated in the experiment.

Materials. A sample of 64 high and 64 low associative frequency words were desired for the list-learning experiment. In order to obtain these words, the 465 words with an associative frequency of 0 and the 191 words with an associative frequency equal to or greater than 50 were initially selected. To try to equate the groups in length in letters, imagery, meaningfulness, and frequency, the 40 longest words, the 40 words lowest in imagery value, the 40 words lowest in meaningfulness, and the 40 words of lowest frequency were removed from the low associative frequency group, and the 12 shortest words, the 12 words highest in imagery, the 12 words highest in meaningfulness, and the 12 words of greatest frequency were removed from the high associative frequency group. This procedure was repeated several times until the mean values for imagery and meaningfulness balanced in the high and low associative frequency groups. By choosing words that were of proper length, as well as of proper frequency, on the last frequency iteration, it was possible to also balance length in letters. Frequency could not be balanced, but the difference between the mean values of the two groups was made relatively small. The difference in the mean values of frequency, however, is not seen as a serious flaw, because the effect of frequency in separate lists of high and low frequency words is small when compared with the difference in mean value of frequency used here (Deese, 1969; Hall, 1954). Table 4 presents the statistics for the dependent variables controlled in the final sample of 64 high and 64 low associative frequency words. Values for associative frequency and for the free-recall measure that was not used in the selection of the words are also included in Table 4 . $T$ tests calculated over the 128 words in the two samples are provided as a descriptive statistic comparing differences between the group means to differences within the groups. If the $t$ value for free recall were squared, it could be considered as an $\mathrm{F}_{2}$ value (Christian et al., 1978; Clark, 1973) for an ANOVA run using Christian et al.'s data. It may be noted that the slight difference between the groups on length, imagery, and meaningfulness are all in the direction that would work against the associative frequency hypothesis.

Procedure. Four lists of 16 high associative frequency words and four lists of $16 \mathrm{low}$ associative frequency words were alternated, uniform lists being used in an attempt to further generalize the results of Rubin (1980) and Experiment 1, which used mixed lists. A second order of presentation was obtained by reversing both the order of the eight lists and the 16 words within each list. Approximately half of the subjects saw each order. Words were presented for $3 \mathrm{sec}$ each using a slide projector. A slide of a three-digit number ended each list. The subjects 
Table 4

Statistics for the High and Low Associative Frequency Groups

\begin{tabular}{|c|c|c|c|c|c|c|c|}
\hline \multirow[b]{2}{*}{ Variable } & \multicolumn{3}{|c|}{ High Group } & \multicolumn{3}{|c|}{ Low Group } & \multirow[b]{2}{*}{ t Test } \\
\hline & Mean & SD & Range & Mean & SD & Range & \\
\hline Length & 5.92 & 1.52 & $4.00-10.00$ & 5.83 & 1.02 & $4.00-7.00$ & .41 \\
\hline Imagery & 5.55 & .93 & $2.77-6.53$ & 5.57 & .69 & 4.436 .77 & .15 \\
\hline Meaningfulness & 6.22 & .73 & $4.04-7.36$ & 6.26 & .66 & $5.32-8.19$ & .33 \\
\hline Kucera-Francis Frequency & 27.26 & 2.65 & $2.00-105.00$ & 9.87 & 2.87 & $2.00-135.00$ & 5.65 \\
\hline Associative Frequency & 189.14 & 2.86 & $50.00-2292.00$ & .00 & .00 & $.00-.00$ & $39.95 *$ \\
\hline Free Recall & .46 & .13 & $.19-.78$ & .36 & .12 & $.06-.84$ & 4.24 \\
\hline
\end{tabular}

Note-The $t$ tests are all based on 128 words, except the free recall measure, which is based on 126 words. As the words are not independent, the $t$ tests must be considered descriptive. All calculations for KuCera-Francis frequency and associative frequency are based on log frequency. The means are, therefore, geometric means, and the standard deviations are conversions from the actual logarithmic ones. $\quad$ *Single-sample $t$ test against a value of 0.

recorded subtractions by 3 from this number for $30 \mathrm{sec}$, at which time they were asked to write their recalls. Verbatim recall was encouraged, but the subjects were encouraged to guess. Thirty seconds after the subjects, who were run in groups, completed the 90 -sec recall period of one list, the next list was presented. A practice list of words, drawn from Paivio et al. (1968), preceded the eight lists analyzed here. Due to a problem with one slide, one high and one matching low associative frequency word were removed from the analysis.

\section{Results}

The high associative frequency words were recalled $61.5 \%$ of the time, as compared to $53.8 \%$ of the time for the low associative frequency words $[\mathrm{t}(69)=7.42$, $\mathrm{p}<.001]$. Considering the first two experiments together, associative frequency appears to have a reliable and substantial effect on the level of recall, both in mixed and uniform lists, even when the other major variables affecting recall are constant. Although one could argue that the actual size of the difference in recall levels obtained in this experiment is not large, any difference found after imagery, meaningfulness, and length in letters are controlled is impressive, especially because such controls are not usually applied in psychology. In fact, given the correlation of associative frequency with these other variables in uncontrolled samples of words, it may be that associative frequency was responsible for part of their effectiveness.

\section{EXPERIMENT 3: A RECOGNITION EXPERIMENT}

The recognition paradigm offers a good test of the availability interpretation of associative frequency. Assuming that the explanation of recognition offered by Mandler (1980) is correct, two processes are used to determine whether a given word appeared on a recent list. One process is a judgment based on familiarity, and the other is a judgment based on success in retrieving words. If high associative frequency words are also high availability words, the familiarity of the word should not be greatly affected by one recent presentation. That is, it should be difficult to distinguish the level of familiarity of a recently presented high associative frequency word and the level of familiarity of the same word if it were not presented. Similarly, it should be easy to distinguish the level of familiarity of a recently presented low associative frequency word and the same word if it were not presented. For example, consider your confidence in judging whether the words "water" and "wigwam" were presented to you in the last hour, both for the case in which the words were targets and for the case in which the words were foils.

The familiarity judgment favors low associative frequency words. The retrieval judgment, as shown in the recall experiments, might seem to favor the high associative frequency words, because these words are easier to retrieve. Again, however, the comparison to a baseline would reverse the direction of the effect. That is, perceived difference in ease of retrieval between words that were and were not on the original list should be greater for low associative frequency words, as one recent presentation should have more of an effect on their ease of retrieval.

Thus, given the availability interpretation of associative frequency and a model of recognition based on familiarity and ease of retrieval judgments, low associative frequency should be recognized better than high. This reversal is the same as is often noted with word frequency (Glanzer \& Bowles, 1976; Mandler, 1980) and could be derived from other models of recognition that can handle the word frequency effect. In fact, the Glanzer and Bowles model explicitly makes use of associative frequency (although it is never measured) to explain the word frequency effect in recognition, as do models of false recognition based on implicit associative responses (Anisfeld \& Knapp, 1968; Underwood, 1965).

\footnotetext{
Method

Subjects. Seventy-five undergraduates drawn from the same population as that of Experiment 2 participated.

Procedure. The 128 words from Experiment 2 were presented to approximately half of the subjects in one long list, alternating
} 
high and low associative frequency words. The reverse order of this list was presented to the remaining subjects. A $1.6 \mathrm{sec}$ presentation rate and the same physical environment as Experiment 2 were used. The $30-s e c$ retention interval was filled with subtraction by $3 \mathrm{~s}$ from a three-digit number. Subjects chose the correct word from among the four alternatives printed on each line of a 128-line form. The subjects were informed of the nature of the task before the words were presented and were instructed to guess if necessary, but to circle one and only one word on each line.

Two sets of forms were used. The foils were identical and identically placed, three foils to a line on both forms. The foils were drawn randomly from the Paivio et al. (1968) words remaining after the targets were selected, with the restriction that their values of associative frequency, length, imagery, meaningfulness, and frequency all fall within the range of values of the target words. For one order, the 128 target words were assigned randomly to the 128 lines of foils. For the other order, a second random assignment was made with the restriction that each line that had a high associative frequency word in the first order would now have a low associative frequency word, and vice versa.

\section{Results}

Subjects correctly recognized $60.8 \%$ of the high associative frequency words and $66.6 \%$ of the low associative frequency words $[\mathrm{t}(74)=6.06, \mathrm{p}<.001]$, a result of approximately the same magnitude as, but in an opposite direction from, the results of Experiment 2.

Experiment 3 was not designed to investigate the role of the foils: They were identically placed for all subjects, confounding their positions with their other properties. Nevertheless, the view of recognition put forth here does make a testable prediction about the foils. Although low associative frequency words should be recognized more often than high associative frequency words, high associative frequency foils should attract more false alarms than low associative frequency words (Anisfeld \& Knapp, 1968; Glanzer \& Bowles, 1976; Underwood, 1965). This is because unless low associative frequency words have appeared recently, they should not seem at all familiar. Using log associative frequency in all calculations, there was a small but statistically significant effect in this direction. The geometric mean associative frequency of the foils was 4.6 , whereas the geometric mean associative frequency of the foils circled by each subject was $5.7[\mathrm{t}(74)=4.20, \mathrm{p}<.001]$.

\section{EXPERIMENT 4: ASSOCIATIVE FREQUENCY AND F AMILIARITY}

The effects of word frequency on recall and recognition have been claimed to be at least partially due to the effects of associative frequency. Of special interest is the claim that people will judge whether they have seen a word among a set of recently presented words by comparison to a baseline that depends, in part, on associative frequency, rather than just on frequency of occurrence. If these claims are true, then it might be expected that people's conscious judgments of the familiarity of words would also depend, in part, on associative fre- quency (Leicht, 1968; Tversky \& Kahneman, 1973). That is, if people judge the probability of past occurrence in a recognition experiment against associative frequency, then they might judge the probability of past occurrence in general using associative frequency. Moreover, if associative frequency is really a measure of availability, then the work of Tversky and Kahneman would suggest not only that associative frequency should affect recall as demonstrated, but also that it should affect familiarity. In particular, if words with high associative frequency are more available, then they should be judged as occurring more frequently than they actually do.

Judgments of familiarity agree quite well with observed word frequency (Carroll, 1971; Shapiro, 1969), well enough that some have considered replacing objective counts of frequency with judgment scales (Carroll, 1971; Frumkina \& Vasilevic, 1974). Nevertheless, systematic differences between the two measures are possible (Rubin, 1976). For instance, Galbraith and Underwood (1973) found that abstract words have greater perceived frequency than concrete words of the same objective frequency, and Tversky and Kahneman (1973) found in a host of tasks that more available words and events were judged to be more frequent.

As a test of the notion that judgments of familiarity are due in part to associative frequency, judgments of familiarity compiled by Paivio (Note 1) will be predicted using measure of frequency of occurrence and associative frequency. To insure that associative frequency is not just one of many variables that have minor, but noticeable, roles in the judgment of familiarity, the variables of concreteness, as used by Galbraith and Underwood (1973), and of length in letters will be included. The latter variable correlates with familiarity and would be easy to use in judging it. In addition, taken together, length in letters, frequency, and concreteness represent three of the six basic factors that Rubin (1980) found to underlie the variables psychologists use to study verbal behavior.

\section{Method}

Materials. Paivio et al.'s (1968) list of 925 nouns was used. The dependent variable, familiarity, comes from a study in which subjects rated printed familiarity on a 7-point scale (Paivio, Note 1) using a procedure similar to Paivio (1968). The independent variables included associative frequency (from Table 1), concreteness (Paivio et al., 1968), length in letters, and frequency (KuXera \& Francis, 1967; Thorndike \& Lorge, 1944). Two measures of frequency were included to help insure that any effects of associative frequency could not be attributed to sampling errors in one of the frequency counts. For the associative frequency and frequency measures, logarithms to the base 10 were taken after all $0 \mathrm{~s}$ were replaced by .5s. For the ThorndikeLorge count, AA and A words were assigned their customary values of 100 and 50 , respectively.

\section{Results}

The multiple regression equation on familiarity, in beta weights, using the above measures, is familiarity = .38 (KuCera \& Francis, 1967) +.37 (Thorndike \& Lorge, 
$1944)+.19$ (associative frequency) +.04 (concreteness $)+.09$ (length) $(n=925, r=.816)$. If the words with an associative frequency of 0 are not included, the equation becomes: familiarity $=.35$ (KuCera \& Francis) +.25 (Thorndike \& Lorge) +.30 (associative frequency) -.02 (concreteness) +.10 (length) $(n=460$, $r=.736)$. The importance of each of the objective frequency counts is reduced by having both in the analysis. If only the Kucera and Francis count is used as a measure of objective frequency, the regression equation becomes familiarity $=.61$ (KuXera \& Francis) +.27 (associative frequency) +.08 (concreteness) +.05 (length) $(\mathrm{n}=925, \mathrm{r}=.789)$, with all words used. For only the words with associative frequency greater than 0 , the equation becomes familiarity $=.50$ (KuCera \& Francis) +.35 (associative frequency) -.004 (concreteness) +.08 (length) $(n=460, r=.716)$. If the words in these equations were considered as independent observations, the effects of associative frequency would be significant at the .001 level in all of the above analyses. Thus, associative frequency appears to be a major contributor to people's judgments of familiarity. In fact, the partial correlation of familiarity with associative frequency, holding both frequency measures constant, is .214 for all 925 nouns and .306 for those with associative frequencies greater than 0 .

The effect of concreteness, noted by Galbraith \& Underwood (1973), appears quite small in this sample, using multiple regression. A multiple regression on familiarity, using only the two frequency measures and concreteness, yields familiarity $=.43$ (Kưera \& Francis, $1967)+.41$ (Thorndike \& Lorge, 1944) +.06 (concreteness) $(\mathrm{n}=925, \mathrm{r}=.805)$. Thus, even with associative frequency removed, the effect here is different than would be expected from Galbraith and Underwood. This difference is difficult to understand but may be due to differences in method. Familiarity, here, is defined by a rating scale, whereas Galbraith and Underwood's result is based on paired comparisons of high- and low-concreteness words.

The correlations between familiarity and the KuxeraFrancis (1967) and Thorndike-Lorge (1944) measures used here were .750 and .759 , respectively. The correlations reported by Shapiro (1969) for a magnitudeestimation measure of familiarity were between .920 and .958, whereas Carroll's (1971) magnitude estimation produced a correlation of .929 for a group of 13 normal subjects and a correlation of .974 for a group of 15 lexicographers. One reason for this difference might be the difference between using a 7-point rating scale and magnitude estimation (Stevens, 1975). Another reason might be that the range of frequency of the words used by Shapiro and by Carroll extends over 2.3 more log units than Paivio et al.'s (1968) nouns do. If this range is reduced by eliminating words at the extremes of Carroll's values, however, his correlation for normal subjects drops only from .929 to .906 , making the difference in method appear to be the more important factor.
The lower correlation between familiarity and frequency used in this study leaves more variance free to be explained by other variables, including associative frequency. The lower correlation, however, does not explain why associative frequency is as successful as it is. Any noise introduced by the methods used need not be systematically related to associative frequency. Associative frequency should be successful only if it accounts for reliable variance in the dependent variables, which is not accounted for by the other variables included in the analyses performed.

\section{GENERAL DISCUSSION}

Two main substantive claims have been made: (1) Associative frequency is a good measure of the availability of isolated words, and (2) associations are not symmetrical. Support for the first claim comes from the superior predictions of recall by associative frequency in an earlier study (Rubin, 1980) and from the observations in this study that high associative frequency words are easier to recall, are judged to be more familiar, are harder to recognize has having occurred on a list, and attract more false alarms when used as foils in a recognition experiment. All but the last observation have been shown to hold when the effects of length in letters, imagery, and meaningfulness are excluded, and the effects of frequency are either excluded or minimized.

Support for the second claim that associations are not symmetrical comes from comparing associative frequency and meaningfulness. Associative frequency is the number of associations going to a word, whereas meaningfulness is the number of associations coming from a word. If associations were symmetrical for any given word, these two values would be the same and the two variables would function equivalently. The values turn out to be different, as shown by the correlations given, and the variables function in different ways. Associative frequency is a better predictor of which words will lead to easy leaming in a paired associate task when the associative frequency values are taken from the response members. Meaningfulness is a better predictor for the stimulus member. Associative frequency has predictive value in recall that is independent of meaningfulness and can affect recall and recognition when meaningfulness is held constant. One implication of this asymmetry is that in an associative network in which the nodes are words, the number of links going to a word is not equal to the number of links coming from a word, an impossible situation unless the links are directional.

One might view associative frequency as a variable in need of explanation rather than as an explanation in itself. A similar criticism could be made, however, of any variable used to predict recall. One could ask, for instance, what causes a word to be highly imageable. On the positive side, associative frequency, unlike many of our independent variables, is not a rating scale, but a count of observed behavior. Although one can wonder 
why some words come to mind more frequently, it is very much like wondering why some words are written more frequently. That is, at present it is hard to think of many concepts that are more basic than associative frequency and could thus provide a satisfactory explanation of it.

\section{REFERENCE NOTE}

1. Paivio, A. Imagery ratings and other norms for 2,448 words. Unpublished manuscript, University of Western Ontario, 1982.

\section{REFERENCES}

ANISFELD, M., \& KNAPP, M. Association, synonymity, and directionality in false recognition. Journal of Experimental Psychology, 1968, 77, 171-179.

Asch, S. E., \& Ebenholtz, S. M. The principle of associative symmetry. Proceedings of the American Philosophical Society, 1962, 106, 135-163.

CARroll, J. B. Measurement properties of subjective magnitude estimates of word frequency. Journal of Verbal Learning and Verbal Behavior, 1971, 10, 722-729.

Chrigtian, J., Bickley, W., Tarka, M., \& Clayton, K. Measures of free recall of 900 English nouns: Correlations with imagery, concreteness, meaningfulness, and frequency. Memory \& Cognition, 1978, 6, 379-390.

Clank, H. H. The language-as-fixed-effect fallacy: A critique of language statistics in psychological research. Journal of Verbal Learning and Verbal Behavior, 1973, 12, 335-359.

DALE, H. C. A. Response availability and short-term memory. Journal of Verbal Learning and Verbal Behavior, 1967, 6, 47-48.

DEESE, J. Frequency of usage and number of words in free recall: The role of association. Psychological Reports, 1960, 7, 337-344.

DEEgE, J. The structure of associations in language and thought. Baltimore: Johns Hopkins Press, 1965.


lists. Bulletin of the Psychonomic Society, 1974, 4, 137-138.

Ekstrand, B. R. Backward associations. Psychological Bulletin, $1966,65,50-64$.

Ervin, S. M. Correlates of associative frequency. Journal of Verbal Learning and Verbal Behavior, 1963, 1, 422-431.

Frincke, G. Word characteristics, associative-relatedness, and the free-recall of nouns. Journal of Verbal Learning and Verbal Behavior, 1968, 7, 366-372.

Frumkina, R. M., \& Vasilevic, A. P. Applying psychometric methods in linguistic research. Linguistics, 1974, 138, 5-29.

Galbraith, R. C., \& Underwood, B. J. Perceived frequency of concrete and abstract words. Memory \& Cognition, 1973, 1, 56-60.

Glanzer, M., \& Bowles, N. Analysis of the word-frequency effect in recognition memory. Journal of Experimental Psychology: Human Learning and Memory, 1976, 2, 21-31.

GREGG, V. Word frequency, recognition, and recall. In J. Brown (Ed.), Recall and recognition. New York: Wiley, 1976.

HaLl, J. F. Learning as a function of word-frequency. American Journal of Psychology, 1954, 67, 138-140.

Horowitz, L. M., Norman, S. A., \& DAy, R. S. Availability and associative symmetry. Psychological Review, 1966, 73, 1 15.

Howes, D. A. On the relation between the probability of a word as an association and in general linguistic usage. Journal of Abnormal and Social Psychology, 1957, 54, 75-85.

Kiss, G. R. Words, associations, and networks. Journal of Verbal Learning and Verbal Behavior, 1968, 7, 707-713.
KISs, G. R. An associative thesaurus of English: Structural analysis of a large relevance network. In A. Kennedy \& A. Wilkes (Eds.), Studies in long-term memory. London: Wiley, 1975.

Kučera, H., \& Francis, W. N. Computational analysis of present-day American English. Providence, R.I: Brown University Press, 1967.

LEICHT, K. L. Recall and judged frequency of implicitly occurring words. Journal of Verbal Learning and Verbal Behavior, $1968,7,918-923$.

MANDLER, G. Recognizing: The judgment of previous occurrence. Psychological Review, 1980, 87, 252-271.

Mandler, G., \& Huttenlocher, J. The relationship between associative frequency, associative ability and paired-associative learning. American Journal of Psychology, 1956, 69, 424-428.

Paivio, A A factor-analytic study of word attributes and verbal learning. Journal of Verbal Learning and Verbal Behavior, $1968,7,41-49$.

Paivio, A. Images and verbal processes. New York: Holt, Rinehart, and Winston, 1971.

Paivio, A., Yuille, J. C., \& Madigan, S. A. Concreteness, imagery, and meaningfulness values for 925 nouns. Journal of Experimental Psychology Monograph, 1968, 76(1, Pt. 2).

PALERMo, D. S., \& Jenkins, J. J. Word association norms. Minneapolis: University of Minnesota Press, 1964.

Pete rs, H. N. The relationship between familiarity of words and their memory value. American Journal of Psychology, 1936, 48, 572-584.

Rubin, D. C. The subjective estimation of relative syllable frequency. Perception \& Psychophysics, 1974, 16, 193-196.

Rubin, D. C. Applying psychometric methods in linguistic research: Some recent advances. Linguistics, 1976, 168, 63-66.

Rubin, D. C. 51 properties of 125 words: A unit analysis of verbal behavior. Journal of Verbal Learning and Verbal Behavior, 1980, 19, 736-755.

Rubin, D. C. First-order approximation to English second-order approximation to English, and orthographic neighbor ratio norm for 925 nouns. Behavior Research Methods \& Instrumentation, 1981, 13, 713-721.

Rubin, D. C., \& Corbett, S. Adaptation-level theory and the free recall of mixed-frequency lists. Bulletin of the Psychonomic Society, 1982, 20, 27-29.

Shapiro, B. J. The subjective estimation of relative word frequency. Journal of Verbal Learning and Verbal Behavior, $1969,8,248-251$.

Skinner, B. F. The verbal summator and a method for the study of latent speech. Journal of Psychology, 1936, 2, 71-107.

Stevens, S. S. Psychophysics: Introduction to its perceptual, neural, and social prospects. New York: Wiley, 1975.

Thorndike, E. L. The fundamentals of learning. New York: Bureau of Publications, Teachers College, 1932.

ThonNdike, E. L., \& LoRge, I. The teacher's word book of 30,000 words. New York: Teachers College Press, 1944.

Tulving, E., \& Pearlstone, Z. Availability versus accessibility of information in memory for words. Journal of Verbal Learning and Verbal Behavior, 1966, 5, 381-391.

Tversky, A., \& Kahneman, D. Availability: A heuristic for judging frequency and probability. Cognitive Psychology, 1973, 5, 207-232.

UNDERWOOD, B. J. False recognition produced by implicit verbal responses. Journal of Experimental Psychology, 1965, 70, $122-129$.

\section{NOTE}

1. A note about the meaning of two of the central terms of this paper needs to be made. The meaning of availability is used in the sense of Asch and Ebenholtz (1962), Thorndike (1932), 
Tversky and Kahneman (1973), and others, and refers to the ease with which something comes to mind. It is, unfortunately, in conflict with Tulving and Pearlstone's (1966) distinction between availability and accessibility: Accessibility comes closer to the present meaning of availability. The meaning of associative frequency is taken from Ervin (1963) and Howes (1957) and refers to the number of times a word is given as an associate, rather than the number of associates a word has. Unfortunately, it is in conflict with Mandler and Huttenlocher's (1956) and others' use of associative frequency as a synonym, or near synonym, for meaningfulness.

\section{(Received for publication May 5, 1982;} revision accepted August 6, 1982.) 